Resenha por: Regiane Fátima Nascimento ${ }^{1}$

\title{
A REGULAÇÃO DOS SERVIÇOS DE SAÚDE MENTAL NO BRASIL: INSERÇÃO DA PSICOLOGIA NO SISTEMA ÚNICO DE SAÚDE E NA SAÚDE SUPLEMENTAR
}

Conselho Federal de Psicologia, Brasília, 2013

${ }^{1}$ Núcleo de Pesquisa em Direito Sanitário, Universidade de São Paulo. São Paulo/SP, Brasil.

Correspondência: Regiane Fátima Nascimento. E-mail: regifati40@hotmail.com.

Recebido em: 22/09/2014. 
Publicada em 2013 pelo Conselho Federal de Psicologia, em parceria com o Núcleo de Pesquisa em Direito Sanitário da Universidade de São Paulo (NAP-DISA/USP) e com o Centro de Estudos e Pesquisas de Direito Sanitário (Cepedisa), a pesquisa "A regulação dos serviços de saúde mental no Brasil: inserção da psicologia no Sistema Único de Saúde e na saúde suplementar" teve como objetivo analisar as principais normas jurídicas que regulam a atenção à saúde mental no Brasil e os serviços oferecidos no âmbito do Sistema Único de Saúde (SUS).

Em oito capítulos, os autores sistematizam desde os aspectos fundamentais relacionados à evolução política, jurídica e institucional até as principais normas jurídicas que regulam o processo de atendimento da saúde mental no país.

A publicação destaca a efetivação das normas que regulam os serviços prestados no âmbito do SUS e os desafios presentes na área da saúde mental, no que diz respeito à prestação de serviços preventivos, serviços de emergência, hospitalares e ambulatoriais, serviços domiciliares e serviços terapêuticos. A pesquisa evidencia as lacunas em relação à atuação das operadoras de planos e seguros de saúde no Brasil - por exemplo, o fato de ainda não estar inscrita na legislação a obrigatoriedade de se prestarem serviços psicológicos, no âmbito da saúde suplementar, que possibilitem ao indivíduo a correta compreensão de sua saúde e dos fatores de risco a que está submetido.

O estudo buscou identificar, entre as normas constitucionais, legais e infralegais de direito sanitário, aquelas que regulam a saúde mental no Brasil e que abarcam os serviços de psicologia e psicoterapia no âmbito da saúde suplementar, segundo o rol de procedimentos previstos no plano de referência de assistência à saúde ${ }^{1}$ para tratamento das doenças previstas na Classificação Estatística Internacional de Doenças e Problemas Relacionados com a Saúde (CID).

A publicação discorre sobre a fiscalização dos serviços de psicologia no âmbito da saúde suplementar e destaca que, no Brasil, os serviços de normatização e fiscalização de profissões regulamentadas são realizados pelos conselhos de classe, o que garante um sistema de autorregulação organizado pelos próprios profissionais que representa uma importante fonte de produção de normas infralegais específicas de direito sanitário, em especial aquelas que implicam a definição dos padrões éticos de comportamento dos profissionais, tratados nos respectivos códigos de deontologia.

Embora, segundo o artigo 198 da Constituição Federal, as ações e os serviços públicos de saúde integrem uma rede de atenção à saúde - o que significa dizer,

\footnotetext{
${ }^{1}$ Conforme o artigo 10 da Lei n. 9.956/1998: “É instituído o plano-referência de assistência à saúde, com cobertura assistencial médico-ambulatorial e hospitalar, compreendendo partos e tratamentos, realizados exclusivamente no Brasil, com padrão de enfermaria, centro de terapia intensiva ou similar, quando necessária a internação hospitalar, das doenças listadas na Classificação Estatística Internacional de Doenças e Problemas Relacionados com a Saúde - CID, da Organização Mundial de Saúde, respeitadas as exigências mínimas estabelecidas no art. 12 [...]". BRASIL. Lei Federal n. 9.956, de 3 de junho de 1998. Dispõe sobre os planos e seguros privados de assistência à saúde. Disponível em: <http://www.planalto.gov.br/ccivil_03/leis/L9656compilado.htm>. Acesso em: 06 mar. 2015.
} 
a priori, que tanto para o sistema público como para o privado está intrínseco o "atendimento integral, com prioridade para as atividades preventivas, sem prejuízo dos serviços assistenciais" (inciso II) -, na análise dos pesquisadores, verifica-se que a proteção dada pela legislação pode não ser suficiente para que os usuários de planos privados de saúde tenham a plena efetivação de seu direito à saúde; os dados descritos nesse estudo indicam que há importantes limitações à cobertura universal.

De acordo com os autores, o campo da saúde mental ainda é pouco referenciado no sistema de saúde suplementar; a Agência Nacional de Saúde Suplementar (ANS) estipula critérios para deferimento da cobertura com ativos garantidores da provisão de risco e, além disso, oferece benefícios às operadoras que aderirem a programas de promoção da saúde e de prevenção de doenças direcionados a seus beneficiários.

A pesquisa destaca, entre outros pontos, que não foram identificadas regras específicas sobre urgência e emergência em saúde mental. Tampouco foram encontradas referências específicas à inclusão de serviços do profissional psicólogo no atendimento de emergência em saúde mental no âmbito da saúde suplementar, diferentemente do que ocorre no SUS.

Ainda de acordo com o estudo, enquanto a cobertura do atendimento na saúde mental é ilimitada no âmbito SUS - respeitando o princípio da integralidade, na saúde suplementar a cobertura é limitada, o que mostra uma concepção restrita da integralidade, condicionada à área geográfica abrangida pelo plano, ao rol de procedimentos mínimos, à limitação de sessões por ano e à segmentação contratada ambulatorial e ou hospitalar.

Outro ponto destacado pela pesquisa trata da não obrigatoriedade de registro das operadoras de planos privados de assistência à saúde junto aos Conselhos Regionais de Psicologia, sendo que, estas mesmas operadoras devem obrigatoriamente estar registradas nos Conselhos Regionais de Medicina e Odontologia (artigo 8º inciso I, Lei n. 9.656/1998). Para os autores, isso pode significar a existência de uma assimetria entre o tratamento dado aos serviços de psicologia no âmbito do SUS e no da saúde suplementar.

Por fim, a pesquisa conclui que a saúde suplementar, tal como regulamentada atualmente, não garante aos consumidores de planos privados de assistência à saúde o pleno exercício do direito à saúde no que concerne à saúde mental, seja no âmbito do atendimento ambulatorial, seja no do atendimento hospitalar.

Regiane Fátima Nascimento - Bacharela em Serviço Social e bolsista no Programa de Aprimoramento Profissional em Direito Sanitário e Advocacia em Saúde do Núcleo de Pesquisa em Direito Sanitário da Universidade de São Paulo. São Paulo/SP, Brasil. E-mail: regifati40@hotmail.com. 